\title{
Direct measurement of the oceanic carbon monoxide flux by eddy correlation
}

\author{
B. W. Blomquist ${ }^{1}$, C. W. Fairall ${ }^{2}$, B. J. Huebert ${ }^{1}$, and S. T. Wilson ${ }^{3}$ \\ ${ }^{1}$ Department of Oceanography, University of Hawaii, Honolulu, HI 96822, USA \\ ${ }^{2}$ NOAA Earth System Research Laboratory, Physical Sciences Division, Boulder, CO 80305, USA \\ ${ }^{3}$ Center for Microbial Oceanography: Research and Education, University of Hawaii, Honolulu, HI 96822, USA
}

Correspondence to: B. W. Blomquist (blomquis@ @awaii.edu)

Received: 31 May 2012 - Published in Atmos. Meas. Tech. Discuss.: 13 July 2012

Revised: 8 October 2012 - Accepted: 21 November 2012 - Published: 18 December 2012

\begin{abstract}
This report presents results from a field trial of ship-based air-sea flux measurements of carbon monoxide (CO) by direct eddy correlation with an infrared-laser trace gas analyzer. The analyzer utilizes Off-Axis IntegratedCavity-Output Spectroscopy (OA-ICOS) to achieve high selectivity for $\mathrm{CO}$, rapid response $(\sim 2 \mathrm{~Hz})$ and low noise. Over a two-day sea trial, peak daytime seawater $\mathrm{CO}$ concentrations were $\sim 1.5 \mathrm{nM}$ and wind speeds were consistently 10 $12 \mathrm{~m} \mathrm{~s}^{-1}$. A clear diel cycle in CO flux with an early afternoon maximum was observed. An analysis of flux error suggests the effects of non-stationarity are important, and air-sea $\mathrm{CO}$ flux measurements are best performed in regions remote from continental pollution sources.
\end{abstract}

\section{Introduction}

Carbon monoxide (CO) is produced in the ocean surface mixed layer by photolysis of chromophoric dissolved organic matter (CDOM) (Wilson et al., 1970; Lamontagne et al., 1971; Zuo and Jones, 1995). Daytime photolytic production and continual consumption by microbes (Conrad and Seiler, $1980,1982)$ leads to a pronounced diel cycle in surface seawater $\mathrm{CO}$ concentration, with a pre-dawn minimum and an early afternoon maximum (Lamontagne et al., 1971; Conrad et al., 1982; Johnson and Bates, 1996; Stubbins et al., 2006; Zafiriou et al., 2008). Considerable variability is possible in both the rate of production (Valentine and Zepp, 1993; Zuo and Jones, 1995) and rate of consumption (Jones, 1991; Jones and Amador, 1993; Johnson and Bates, 1996). In two detailed studies of the water column $\mathrm{CO}$ budget, ventilation to the atmosphere was less significant than loss to microbial consumption (Bates et al., 1995; Zafiriou et al., 2003).

Although marine emissions represent a minor fraction of the global CO budget (Bates et al., 1995; Stubbins et al., 2006), the ocean may be a significant source of CO to the remote marine boundary layer in the Southern Hemisphere (Erickson and Taylor, 1992). In addition, CO is recognized as a useful tracer for studies of sea surface mixed layer processes because it couples to biological, photochemical, and physical mixing dynamics (Najjar and Erickson III, 1995; Zafiriou et al., 2008).

Due to the lack of a suitable direct flux measurement, previous studies of oceanic $\mathrm{CO}$ emissions utilize empirical gas exchange formulations (e.g., Wanninkhof, 1992; Nightingale et al., 2000). CO solubility in seawater is quite low. Empirical models of air-sea gas exchange typically focus on gases of similarly low solubility (e.g., $\mathrm{Rn}$ or $\mathrm{He} / \mathrm{SF}_{6}$ dual tracer methods), so these formulations may also provide a reasonable representation of $\mathrm{CO}$ transfer. An eddy correlation flux measurement allows a practical test of this assumption. In a more fundamental sense, direct measurement of the $\mathrm{CO}$ flux facilitates development of physical gas transfer algorithms specifying the solubility dependence of the gas exchange coefficient (e.g., Fairall et al., 2011, and references therein).

In this submission we present results from a short field trial of a new method for direct measurement of the oceanic $\mathrm{CO}$ flux by eddy correlation. To our knowledge, this is the first reported CO flux measurement from a ship. The data set presented here is brief. Our intent in submitting this article is to (1) present evidence that air-sea flux measurements of $\mathrm{CO}$ are feasible with current state-of-the-art instrumentation, and 
(2) examine flux error related to departure from stationary conditions (see Businger, 1986, for a discussion of stationarity and flux measurement).

\section{Experiment}

An LGR model 907-0014 N 2 O/CO analyzer (Los Gatos Research, Inc.) was used in this trial. This instrument employs a continuous narrow-band infrared laser source for Off-Axis Integrated-Cavity-Output Spectroscopy (OA-ICOS) absorption measurements of $\mathrm{N}_{2} \mathrm{O}$, CO and $\mathrm{H}_{2} \mathrm{O}$ (O'Keefe et al., 1999; Baer et al., 2002). In this test, we use a 200-tube Nafion air drier (Perma Pure PD-200T-24-SS) to reduce the dew point to $<-10^{\circ} \mathrm{C}$, yielding essentially dry-air concentration values. The analyzer data rate is $10 \mathrm{~Hz}$, but, as we note below, in this configuration at a sample flow of $\sim 10 \mathrm{std} \mathrm{L} \mathrm{min}^{-1}$ frequency response is $\sim 1-2 \mathrm{~Hz}$. Air was subsampled from a $20 \mathrm{~m}$ long high-flow Teflon inlet ( $3 / 8^{\prime \prime}$ ID) drawing air at $\sim 80 \mathrm{std} \mathrm{L} \mathrm{min}^{-1}$. The air inlet, sonic anemometer (Gill Model R2) and a six-channel motion sensor (Systron-Donner MotionPak) were mounted at the top of a $10 \mathrm{~m}$ meteorological tower on the bow of the University of Hawaii research vessel Kilo Moana. The motion sensor was located $0.6 \mathrm{~m}$ below the sonic volume. A short pulse of nitrogen injected at the inlet tip each hour facilitated precise synchronization of wind and CO measurements. Procedures for correcting wind data for ship motion interference have been described previously (Edson et al., 1998; Blomquist et al., 2010).

The mean ten-minute $\mathrm{CO}$ variance spectrum (Fig. 1) shows a "pink" background noise $\left(\sim 1 / f^{\mathrm{n}}\right)$ in addition to the $-5 / 3$ dependency due to turbulent dissipation. The integrated noise variance over the flux bandpass $(0.00167$ to $2 \mathrm{~Hz})$ is $0.015 \mathrm{ppb}^{2}\left(\sigma_{\mathrm{co}}=0.12 \mathrm{ppb}\right)$. An instrument artifact signal is evident at $3 \mathrm{~Hz}$, but this is beyond the flux frequency response and has been filtered from the data. A comparison of shipboard spectra with laboratory data (not shown) shows negligible analyzer sensitivity to ship motion.

Fluxes are derived from ten-minute segments of $\mathrm{CO}$ and vertical wind velocity data with $50 \%$ overlap of successive segments (i.e., 11 ten-minute segments per hour). The linear trend is subtracted from each segment and a Hamming window function applied to limit leakage of low frequency variance unrelated to surface flux. The slope from the linear trend in $\mathrm{CO}$ is retained as a measure of $\partial \mathrm{CO} / \partial t$ for each segment. Flux is computed as the area of the cospectrum.

This gas inlet has been used extensively for dimethyl sulfide (DMS) flux measurements and the transfer characteristics studied in detail (Blomquist et al., 2010). At flow rates $\geq 80 \mathrm{~L} \mathrm{~min}^{-1}$, frequency attenuation in the main sample line is not significant; the half-power frequency is $\sim 10 \mathrm{~Hz}$. The Nafion air dryer produces the greatest signal attenuation, lowering the half-power frequency to $\sim 1-2 \mathrm{~Hz}$. The frequency response of the $\mathrm{CO}$ analyzer in this configuration is quoted by the manufacturer at $1-2 \mathrm{~Hz}$ as well. For DMS, we

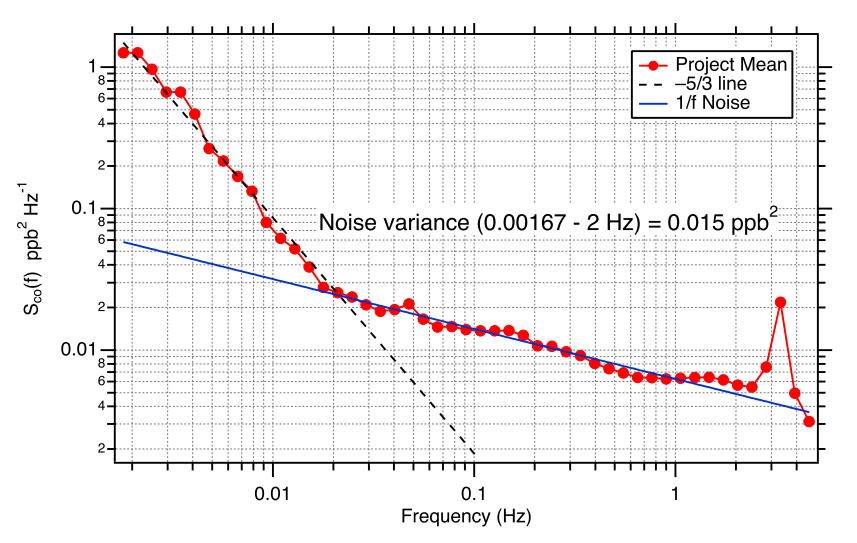

Fig. 1. Mean bin-averaged CO variance spectrum for $\sim 400$ tenminute data segments at sea. Valid data segments were selected using criteria described in Sect. 3. The peak at $3 \mathrm{~Hz}$ is an analyzer artifact.

have consistently found a flux attenuation correction of 4$5 \%$ at wind speeds comparable to this project (e.g., Yang et al., 2011). We therefore apply the same correction to CO flux. In the future a more thorough examination of flux losses is warranted. However, bias associated with imprecision in this correction is unlikely to alter the conclusions of this report.

Ten-minute flux results are selected to eliminate periods unsuitable for eddy correlation measurements. Data acquisition was continuous, but roughly one-third of the ten-minute flux values over the two-day period were discarded on the basis of selection criteria. Selection limits relating to sampling conditions are: relative wind direction within $\pm 60^{\circ}$ of the bow, standard deviation in relative wind direction $<10^{\circ}$, and heading change $<25^{\circ}$ in ten minutes. In addition, it was necessary to impose stationarity criteria limiting the magnitude of $\partial \mathrm{CO} / \partial t$ and horizontal turbulent flux, as described in Sect. 4.

\section{Results}

The CO flux trial was conducted on a routine cruise to the Hawaii Ocean Time-series (HOT) station ALOHA, located at $22^{\circ} 45^{\prime} \mathrm{N}, 158^{\circ} \mathrm{W}$ (cruise HOT-238, 18-22 December 2011). Over two days of sampling on-station, wind speed was consistently $10-12 \mathrm{~m} \mathrm{~s}^{-1}$, and relative wind direction remained within $\pm 20^{\circ}$ of the bow. Seawater $\mathrm{CO}$ concentration at $5 \mathrm{~m}$ depth (Fig. 2) was measured from selected daytime CTD (conductivity, temperature, depth) casts using the method of Xie et al. (2002). An afternoon maximum of $\sim 1.5 \mathrm{nM}$ is evident. Nighttime samples were not analyzed but were most likely $\leq 0.5 \mathrm{nM}$ based on data from prior cruises, implying a mean daily concentration of $<1 \mathrm{nM}$. Seawater CO measurements at station ALOHA on prior cruises since 2008 (also Fig. 2) show a diel pattern typical for blue water regions in the Pacific and Atlantic (e.g., Johnson and Bates, 


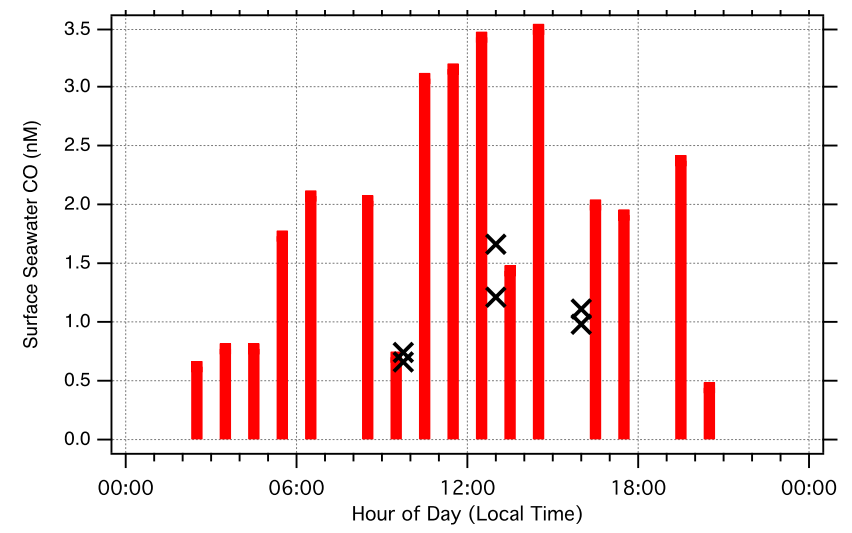

Fig. 2. Diel cycle in seawater CO at station ALOHA (local time). Crosses: this cruise. Bars: bin-averaged results from previous HOT cruises over all seasons since 2008 .

1996; Stubbins et al., 2006; Zafiriou et al., 2008): an early afternoon maximum of $2-3 \mathrm{nM}$ and mean daily concentration of $\sim 1 \mathrm{nM}$. In contrast, peak seawater CO concentrations in Fig. 2 for this trial were about half the typical value, providing a stringent test of the flux measurement method.

Figure 3 is a time series of hourly $\mathrm{CO}$ flux for the cruise, computed as the mean of all ten-minute flux measurements each hour meeting selection criteria. Figure 4 shows tenminute results bin-averaged to hour-of-day (local time). The diel cycle in $\mathrm{CO}$ flux from Fig. 4 closely mirrors the cycle in seawater concentration in Fig. 2, with a pre-dawn minimum and early afternoon maximum.

For a seawater $\mathrm{CO}$ concentration of $1.5 \mathrm{nM}$ at the peak in the flux diel cycle (02:00-03:00 p.m. LT - local time), the $\mathrm{CO}$ gas transfer coefficient computed from Eq. (1) at the reference Schmidt number $660\left(k_{660}\right)$ is $41 \mathrm{~cm} \mathrm{~h}^{-1}$;

$k_{660}=\frac{F_{\mathrm{co}}}{\alpha_{\mathrm{co}} \Delta P_{\mathrm{co}}}\left(\frac{S c_{\mathrm{co}}}{660}\right)^{1 / 2}$,

where $F_{\text {co }}$ is flux, $\alpha_{\text {co }}$ is dimensionless solubility, $\Delta P_{\text {co }}$ is the interfacial concentration gradient, $\left(C_{\mathrm{sw}} / \alpha-C_{\text {air }}\right)$, and $S c_{\text {co }}$ is the Schmidt number in seawater at ambient temperature. For these conditions, at $U_{10} \sim 11 \mathrm{~m} \mathrm{~s}^{-1}$, the Wanninkhof (1992) gas transfer model gives $k_{660}=38 \mathrm{~cm} \mathrm{~h}^{-1}$; Nightingale et al. (2000) gives $k_{660}=29 \mathrm{~cm} \mathrm{~h}^{-1}$; McGillis et al. (2001) is $k_{660}=40 \mathrm{~cm} \mathrm{~h}^{-1}$; and Woolf (1997) yields $k_{660}=40 \mathrm{~cm} \mathrm{~h}^{-1}\left(\alpha, S c\right.$ and $k_{660}$ computed using the Rscripts of Johnson, 2010). Clearly, the observed $k_{660}$ is close to the expected value based on several of these models, but with limited data it is difficult to draw too much from this agreement. More extensive sampling of the seawater CO concentration is necessary to critically assess the observed transfer coefficient.

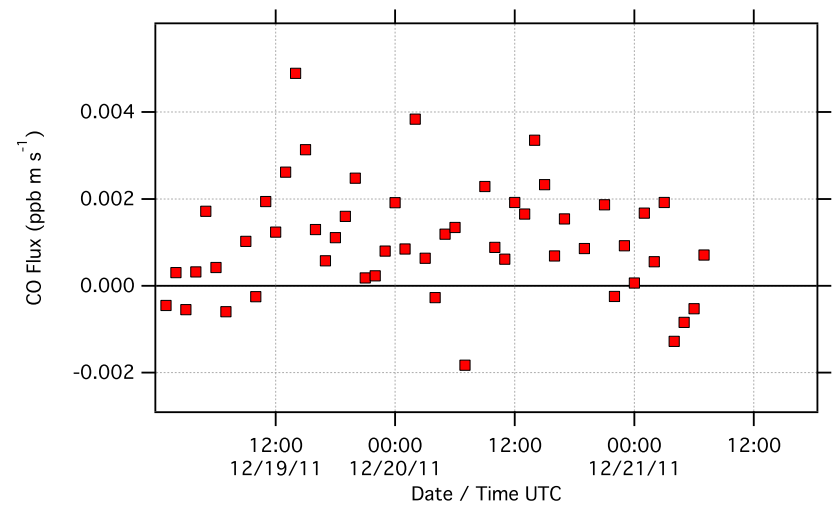

Fig. 3. A time series of hourly mean CO flux over the two-day field test.

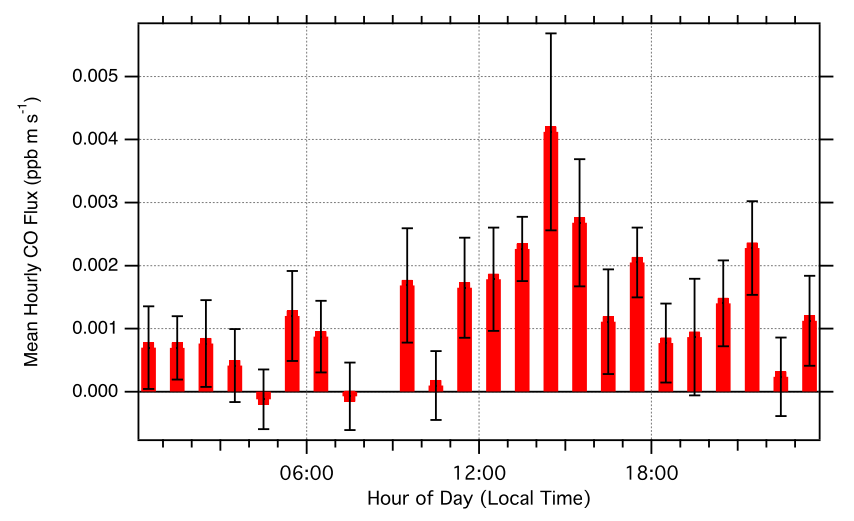

Fig. 4. Diel cycle in CO flux over a two-day period at station ALOHA. Error bars are standard error of the mean.

\section{Sources of flux uncertainty}

Rowe et al. (2011) have analyzed sensor resolution requirements for eddy correlation measurements. For the conditions of this study and the noise level of the $\mathrm{CO}$ analyzer, their analysis predicts a $60 \%$ random error for hourly average $\mathrm{CO}$ flux measurements at a seawater concentration of $0.5 \mathrm{nM}$. In this test, however, scatter in hourly $\mathrm{CO}$ flux from midnight to 06:00 a.m. LT (when seawater CO is $\sim 0.5 \mathrm{nM}$ ) suggests a larger error: $0.00063 \pm 0.00118 \mathrm{ppb} \mathrm{m} \mathrm{s}^{-1}$ or $187 \%$ as the relative standard deviation.

The expected CO variance from surface flux may be predicted from similarity theory as a function of friction velocity $\left(u_{*}\right)$ and flux magnitude $\left(\left|\overline{w^{\prime} \mathrm{co}^{\prime}}\right|\right)$ (Fairall et al., 2000; Blomquist et al., 2010). Assuming neutral stability, the relationship takes the form

$\sigma_{\mathrm{co}, \operatorname{sim}}=3\left|\overline{w^{\prime} \mathrm{co}^{\prime}}\right| / u_{*}$.

As a point of comparison, data for similarity-predicted and observed variance in DMS and CO concentration are shown in Table 1 . The observed DMS standard deviation $\left(\sigma_{\mathrm{obs}}\right)$ from a cruise in the Sargasso Sea is quite close to the similarity estimate $\left(\sigma_{\text {sim }}\right)$. This is reasonable, as the sea surface is the sole 
Table 1. Comparison of parameters for DMS and CO flux measurements in two field studies.

\begin{tabular}{llll}
\hline Parameter & DMS & CO & Notes \\
\hline Mean atm. conc. $(\mathrm{ppb})$ & 0.100 & 100 & \\
Atm. lifetime $(d)$ & $2-3$ & 50 & \\
Sea-air $\Delta P(\mathrm{ppb})$ & 6.6 & 1668 & {$[\mathrm{DMS}]=2.6 \mathrm{nM},[\mathrm{CO}]=1.5 \mathrm{nM}$} \\
SST $\left({ }^{\circ} \mathrm{C}\right)$ & 28 & 22 & \\
Solubility, $\alpha$ & 8.9 & 0.019 & dimensionless liq/gas \\
$U_{10}\left(\mathrm{~m} \mathrm{~s}^{-1}\right)$ & 6 & 11 & \\
$k\left(\mathrm{~cm} \mathrm{~h}^{-1}\right)$ & 10 & 45 & at ambient SST and Sal \\
$u_{*}\left(\mathrm{~m} \mathrm{~s}^{-1}\right)$ & 0.2 & 0.4 & \\
Flux $\left(\mathrm{ppb} \mathrm{m} \mathrm{s}{ }^{-1}\right)$ & 0.0016 & 0.0040 & $F=\alpha k \Delta P$ \\
$\sigma_{\text {sim }}(\mathrm{ppb})$ & 0.021 & 0.030 & from similarity \\
$\sigma_{\mathrm{obs}}(\mathrm{ppb})$ & 0.020 & 0.126 & observed minus sensor noise \\
$\sigma_{\text {sim }} / \sigma_{\mathrm{obs}}$ & 1 & 0.24 & \\
\hline
\end{tabular}

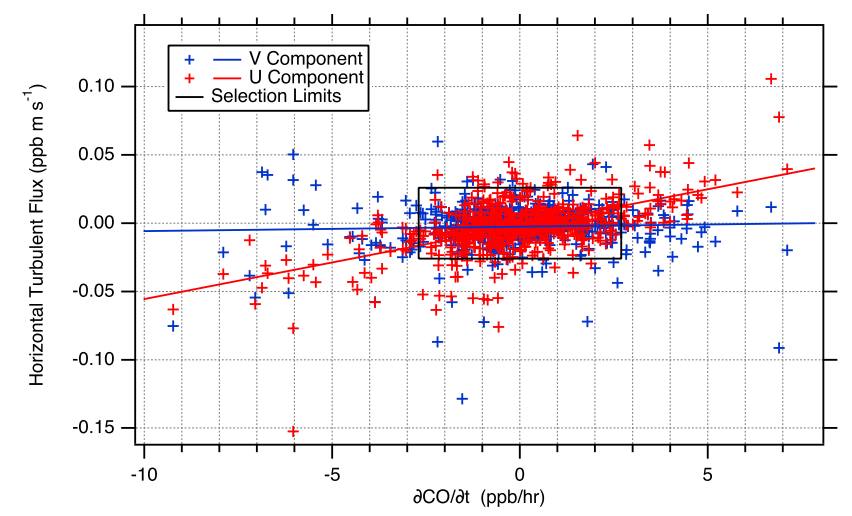

Fig. 5. Trend in $\partial \mathrm{CO} / \partial t$ and along-wind $\left(\overline{u^{\prime} \mathrm{co}^{\prime}}\right)$ and cross-wind $\left(\overline{v^{\prime} \mathrm{co}^{\prime}}\right)$ components of horizontal turbulent flux. Data are tenminute values which meet basic sampling criteria. The bounding box shows selection limits, computed here as the $80 \%$ confidence limit of the mean in each variable. Results outside the bounding box are excluded on the basis of stationarity criteria, limiting the excessive influence of $\mathrm{CO}$ variance from non-surface flux sources.

source of DMS, and its atmospheric lifetime is sufficiently short (2-3 days) to limit the influence of advection from distant sources. However, $\sigma_{\text {obs }}$ for $\mathrm{CO}$ is seen to be four times greater than the similarity-predicted value, further suggesting additional $\mathrm{CO}$ variance from non-surface-flux sources.

Conditions relating to non-stationarity are an obvious source of additional error. Small gradients in CO concentration can yield variance from horizontal turbulent flux which greatly exceeds variance from surface flux, even for typically clean conditions in the remote marine boundary layer at station ALOHA, where the relative standard deviation in ten-minute mean $\mathrm{CO}$ concentration was just $2 \%$ over two days on-station. Figure 5 illustrates the relationship between components of the horizontal turbulent flux and $\partial \mathrm{CO} / \partial t$. A positive correlation exists between the alongwind component of horizontal flux $\left(\overline{u^{\prime} c^{\prime}}\right)$ and $\partial \mathrm{CO} / \partial t$, indicating advection of the $\mathrm{CO}$ gradient past the ship. For numerous samples, horizontal turbulent flux is many times larger than the expected magnitude of $\mathrm{CO}$ surface flux.

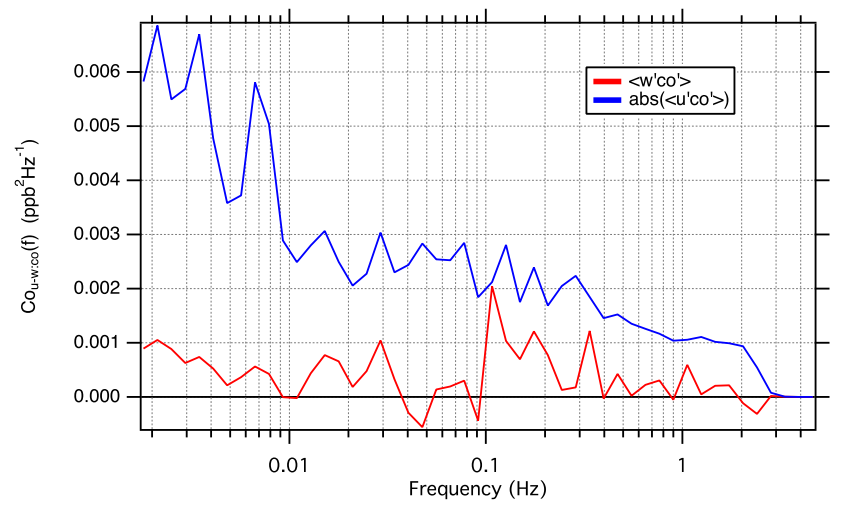

Fig. 6. Mean cospectra illustrating vertical $\left(\overline{w^{\prime} \mathrm{co}^{\prime}}\right.$, red $)$ and horizontal $\left(\left|\overline{u^{\prime} \mathrm{co}^{\prime}}\right|\right.$, blue) CO turbulent flux for $\sim 35$ selected ten-minute afternoon flux segments (01:00-04:00 p.m. LT). Horizontal flux is computed as the mean of absolute values. After eliminating periods of excessive non-stationarity, the magnitude of horizontal turbulent flux is still several times greater than the vertical flux.

The following additional criteria were therefore applied to eliminate ten-minute segments with excessive gradient influence: $|\partial \mathrm{CO} / \partial t|<2.7 \mathrm{ppbh}^{-1}$ and $\left|\overline{u^{\prime} c^{\prime}}\right|<0.026 \mathrm{ppb} \mathrm{m} \mathrm{s}^{-1}$ (shown as a bounding box in Fig. 5).

Even for samples which meet these criteria, the magnitude of $\left|\overline{u^{\prime} c^{\prime}}\right|$ is large compared to $\overline{w^{\prime} c^{\prime}}$. Figure 6 presents cospectra for $\overline{w^{\prime} c^{\prime}}$ and $\left|\overline{u^{\prime} c^{\prime}}\right|$, representing mean fluxes for selected early afternoon ten-minute segments (35 segments, 01:00-04:00 p.m. LT). The $\overline{w^{\prime} c^{\prime}}$ cospectrum is positive but noisy due to limited sample size and the effects of residual $\mathrm{CO}$ variance from other sources. The integrated area of the $\left|\overline{u^{\prime} c^{\prime}}\right|$ cospectrum is quite large, with a significant component at low frequencies mirrored in the $\mathrm{CO}$ variance spectrum (Fig. 1). The mean absolute horizontal turbulent flux from all ten-minute segments meeting selection criteria $\left(\left\langle\left|\overline{u^{\prime} c^{\prime}}\right|\right\rangle_{\text {all }}\right)$ is $0.008 \mathrm{ppb} \mathrm{m} \mathrm{s}^{-1}\left(\left\langle\overline{u^{\prime} c^{\prime}}\right\rangle_{\text {all }}=-0.0034 \pm 0.0091 \mathrm{ppb} \mathrm{m} \mathrm{s}^{-1}\right)$, or eight times greater than the mean vertical flux $\left(\left\langle\overline{w^{\prime} c^{\prime}}\right\rangle_{\text {all }}\right)$ of $0.001 \mathrm{ppb} \mathrm{m} \mathrm{s}^{-1}$.

The scalar variance budget production term associated with CO turbulent flux in a mean gradient is (Stull, 1988)

$-2 \overline{u_{i}^{\prime} \operatorname{co}^{\prime}} \frac{\partial \overline{\mathrm{CO}}}{\partial x_{i}}$,

where $u_{i}$ and $x_{i}$ specify the full turbulent wind field. From similarity theory, an estimate for the vertical CO gradient is

$\frac{\partial \overline{\mathrm{CO}}}{\partial z}=-\frac{\overline{w^{\prime} \mathrm{co}^{\prime}}}{\kappa u_{*} z}$,

which is $\sim 3.5 \times 10^{-4} \mathrm{ppb} \mathrm{m}^{-1}\left(0.35 \mathrm{ppb} \mathrm{km}^{-1}\right)$ for mean conditions of this test (i.e., mean flux $=0.001 \mathrm{ppb} \mathrm{m} \mathrm{s}^{-1}$; $u_{*}=0.4 \mathrm{~m} \mathrm{~s}^{-1}$; measurement height, $z=18 \mathrm{~m}$; and the von Karman constant $\kappa=0.4$ ). The terms (Eq. 3) for horizontal and vertical flux components are therefore comparable when $\partial \overline{\mathrm{CO}} / \partial x \sim 4.3 \times 10^{-5} \mathrm{ppb} \mathrm{m}^{-1}$ (4.3 ppb per $\left.100 \mathrm{~km}\right)$. This 
is a very low threshold gradient for a species with a mean background concentration of $60-150 \mathrm{ppb}$. Assuming a CO gradient aligned with mean wind at $\bar{u}=10 \mathrm{~m} \mathrm{~s}^{-1}$, this corresponds to $|\partial \mathrm{CO} / \partial t|=1.5 \mathrm{ppbh}^{-1}$, or approximately half the $2.7 \mathrm{ppb} \mathrm{h}^{-1}$ selection limit. The stationarity criteria therefore limit the variance from horizontal turbulent flux to approximately twice the variance from mean surface flux. In this test, this is sufficient to eliminate the majority of outlier observations.

\section{Flux detection limit}

To investigate the flux detection limit, we examine theoretical error as a function of air-sea concentration gradient, $\Delta P_{\mathrm{co}}$, and wind speed, $u$. Flux error may be specified as a function of variance in both vertical wind $(w)$ and scalar (CO) measurements, where $\mathrm{CO}$ variance is composed of an atmospheric vertical turbulent flux component $\left(\sigma_{\mathrm{co}_{\mathrm{a}}}^{2}\right)$ and an "other noise variance" component $\left(\sigma_{\mathrm{co}_{\mathrm{n}}}^{2}\right.$, from analyzer white noise, etc.), and where $T$ is sampling time in seconds (after Fairall et al., 2000).

$\delta F_{\mathrm{co}}=\frac{2 \sigma_{\mathrm{w}}}{\sqrt{T}}\left[\sigma_{\mathrm{co}_{\mathrm{a}}}^{2} \tau_{\mathrm{wco}}+\sigma_{\mathrm{co}_{\mathrm{n}}}^{2} \tau_{\mathrm{co}_{\mathrm{n}}}\right]^{1 / 2}$

The two terms in Eq. (5) are assumed to be independent, with characteristic integral time scales $(\tau)$. From nighttime flux measurements under conditions where $\Delta P_{\text {co }}$ is very low (and therefore $\sigma_{\mathrm{co}_{\mathrm{a}}}^{2} \sim 0$ ), we can solve Eq. (5) for the "other noise" term, yielding $\sigma_{\mathrm{co}_{\mathrm{n}}}^{2} \tau_{\mathrm{co}_{\mathrm{n}}}=0.00041$. Using similarity relationships to represent $\sigma_{\mathrm{co}_{\mathrm{a}}}^{2}, \sigma_{\mathrm{w}}$ and $\tau_{\mathrm{wco}}$, and employing empirical functions for the stability dependence of these parameters (see Blomquist et al., 2010) yields an expression for error as a function of $u$ and $u_{*}$, which can be further extended to the following relationship for $\Delta P_{\mathrm{co}}(u)$ (Eq. 6) by assuming an arbitrary error condition (e.g., $\delta F / F=1$, or $100 \%$ error) and substitution of the standard flux formulation: $F_{\mathrm{co}}=\alpha k(u) \Delta P_{\mathrm{co}}$.

$$
\begin{aligned}
\Delta P_{\mathrm{co}}(u)= & \frac{2 \times 1.25 u_{*} f_{\mathrm{w}}(z / L)}{\alpha k(u) \sqrt{3600}}\left[\left(\frac{3 F_{\mathrm{co}} f_{\mathrm{c}}(z / L)}{u_{*}(u)}\right)^{2}\right. \\
& \left.\frac{2.8 z f_{\tau}(z / L)}{\overline{u_{\mathrm{r}}}}+0.00041\right]^{1 / 2}
\end{aligned}
$$

Here, $f_{i}(z / L)$ are functions defining stability dependence (unity for neutral conditions assumed here), $\overline{u_{\mathrm{r}}}$ is mean relative wind speed (equivalent to $\bar{u}$ if the ship is not moving), and $k(u)$ is the gas transfer coefficient function. For CO, $k(u)$ may be estimated from a cubic wind speed dependence (e.g., Edson et al., 2011). An estimate for $u_{*}(u)$ may be obtained by assuming a roughness length typical of the open ocean $(\sim 0.0003 \mathrm{~m})$, or by a fit to observed $u_{*}$, or from a fit to bulk flux model derived $u_{*}$ (e.g., COARE 3.0). Note that in Eq. (6), $F_{\mathrm{co}}$ is dependent on $\Delta P_{\mathrm{co}}$ and $u$, so an iterative

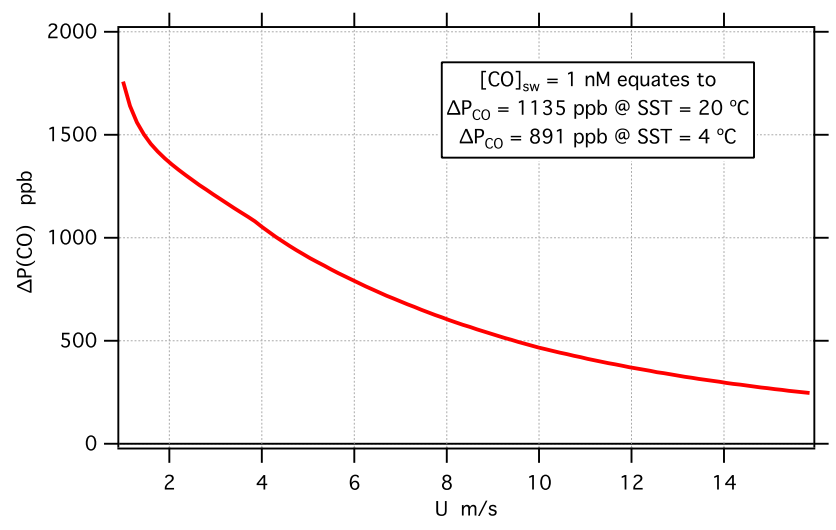

Fig. 7. The flux detection limit criterion expressed as $\Delta P_{\text {co }}$ ppb for $\delta F / F=1$ ( $100 \%$ error in observed CO flux) versus wind speed for $1 \mathrm{~h}$ sampling time under neutral stationary conditions.

solution is necessary. Alternately, Eq. (6) may be further rearranged and solved for $\Delta P_{\mathrm{co}}$ following substitution for $F_{\mathrm{co}}$.

The detection limit criterion $\Delta P_{\mathrm{co}}(u)$ computed from Eq. (6) is shown in Fig. 7. This curve should be a theoretical limit under neutral stationary conditions (the similarity functions assume stationarity), but in fact it may be an upper limit, as $\sigma_{\mathrm{co}_{\mathrm{a}}}^{2}$ is not exactly zero in the empirical determination of the "other error" term above. We also note that, other things being equal, as SST (sea surface temperature) decreases so does $\Delta P_{\mathrm{co}}$, and therefore flux error increases.

Early afternoon conditions for this field trial $\left(\Delta P_{\mathrm{co}}=1700 \mathrm{ppb}, \quad u=11 \mathrm{~m} \mathrm{~s}^{-1}\right)$ lie a factor of three above the curve in Fig. 7, implying an expected error of $33 \%$ for hourly mean flux at the peak in the diel cycle. This is approximately the observed error from Fig. 4 (22-37\% relative error at 01:00-03:00 p.m.LT). Results in Fig. 4 represent the average of all 10-min flux measurements for each hour which meet selection criteria, and in this case the afternoon values include only a little more than one hour of total sampling time, which is approximately the sampling time assumed in Fig. 7. The detection limit presented in Fig. 7 supports the conclusion that oceanic $\mathrm{CO}$ flux measurements are feasible under favorable conditions with appropriate selection criteria.

\section{Conclusions}

The analytical performance of a commercially available infrared OA-ICOS trace gas analyzer is sufficient for shipbased flux measurements of $\mathrm{CO}$ at moderate-to-high wind speeds when seawater concentration is $>1 \mathrm{nM}$. A clear diel cycle in $\mathrm{CO}$ flux, mirroring the cycle in seawater concentration, was observed over two days at a research site near Oahu in the oligotrophic North Pacific subtropical gyre. $\mathrm{CO}$ flux measurements by eddy correlation demonstrated here are a potentially important development for studies of 
biogeochemical and physical dynamics in the ocean's surface mixed layer. Additionally, $\mathrm{CO}$ is an important low solubility end-member in the spectrum of gases involved in airsea exchange. As such, it should exhibit significant bubblemediated gas exchange enhancement at moderate-to-high wind speeds, providing an interesting and important test of physical gas transfer theory.

The effects of non-stationarity are clearly significant for $\mathrm{CO}$. The moderately long atmospheric lifetime of $\mathrm{CO}$ ( $\sim 50$ days), combined with vigorous natural and anthropogenic sources, yields a high, variable background atmospheric concentration of $\sim 100 \mathrm{ppb}$ in the Northern Hemisphere and half that value in the Southern Hemisphere. CO variance from horizontal turbulent diffusion of atmospheric gradients as small as $1-2 \%$ of the mean concentration per $100 \mathrm{~km}$ reduces precision of the eddy correlation flux measurement. Removing 10-min flux values which exhibit excessive horizontal flux or $\partial \mathrm{CO} / \partial t$ (Fig. 5) is critical to reducing error to near the theoretical limit and resolving the diel cycle in $\mathrm{CO}$ flux. These conclusions may also apply to flux measurements of other long-lived gases with high mean background concentrations.

In practice, ideal stationarity is never realized in the field and the question "How much non-stationarity is too much?" is an interesting one. The answer probably depends on the nature of the scalar and the scientific question to be addressed. Criteria are often somewhat subjective. In this case, flux data in Fig. 5 show a clear central cluster surrounded by a widely scattered cloud of outliers. Limits were chosen to include the densest portion of the central cluster. Furthermore, it is apparent from Fig. 5 that $\partial \mathrm{CO} / \partial t$ shows the greatest range as an indicator of non-stationary conditions, but it is not always sufficient. Some samples exhibit significant horizontal turbulent flux and low $\partial \mathrm{CO} / \partial t$. It therefore seems wise to examine stationarity from a variety of perspectives. These considerations may impose stringent location selection criteria for future $\mathrm{CO}$ air-sea flux studies. On the basis of this test, conditions at station ALOHA appear suitable and many locations in the Southern Hemisphere should be equally acceptable.

Acknowledgements. The authors gratefully acknowledge support from NSF grant AGS-1036062 and NOAA Climate Program Office, Climate Observation Division. We are also grateful for the support of the officers and crew of the University of Hawaii R/V Kilo Moana and Craig Nosse and Matt Church of the HOT program. The authors further acknowledge Ian Faloona for helpful comments and suggestions during preparation of this manuscript. We are grateful to Doug Baer and Robert Provencal of LGR for providing the $\mathrm{CO}$ analyzer used in this work.

Edited by: M. Sipilä

\section{References}

Baer, D. S., Paul, J. B., Gupta, M., and O'Keefe, A.: Sensitive absorption measurements in the near-infrared region using off-axis integrated-cavity-output spectroscopy, Appl. Phys. B, 75, 261265, doi:10.1007/s00340-002-0971-z, 2002.

Bates, T. S., Kelly, K. C., Johnson, J. E., and Gammon, R. H.: Regional and seasonal variations in the flux of oceanic carbon monoxide to the atmosphere, J. Geophys. Res., 100, 2309323101, 1995.

Blomquist, B. W., Huebert, B. J., Fairall, C. W., and Faloona, I. C.: Determining the sea-air flux of dimethylsulfide by eddy correlation using mass spectrometry, Atmos. Meas. Tech., 3, 1-20, doi:10.5194/amt-3-1-2010, 2010.

Businger, J. A. : Evaluation of the accuracy with which dry deposition can be measured with current micrometeorological techniques, J. Clim. Appl. Meteorol., 25, 1100-1124, 1986.

Conrad, R. and Seiler, W.: Photooxidative production and microbial consumption of carbon monoxide in seawater, FEMS Micro. Lett., 9, 61-64, 1980.

Conrad, R. and Seiler, W.: Utilization of traces of carbon monoxide by aerobic oligotrophic microorganisms in ocean, lake and soil, Arch. Microbiol., 132, 41-46, 1982.

Conrad, R., Seiler, W., Bunse, G., and Giehl, H.: Carbon monoxide in seawater (Atlantic Ocean), J. Geophys. Res., 87, 8839-8852, 1982.

Edson, J. B., Hinton, A. A., Prada, K. E., Hare, J. E., and Fairall, C. W.: Direct covariance flux estimates from mobile platforms at sea, J. Atmos. Ocean. Tech., 15, 547-562, 1998.

Edson, J. B., Fairall, C. W., Bariteau, L., Zappa, C. J., CifuentesLorenzen, A., McGillis, W. R., Pezoa, S., Hare, J. E., and Helmig, D.: Direct covariance measurement of $\mathrm{CO}_{2}$ gas transfer velocity during the 2008 Southern Ocean Gas Exchange Experiment: Wind speed dependency, J. Geophys. Res., 116, C00F10, doi:10.1029/2011JC007022, 2011.

Erickson III, D. J. and Taylor, J. A.: 3-D tropospheric CO modeling: the possible influence of the ocean, Geophys. Res. Lett., 19, 1955-1958, 1992.

Fairall, C. W., Hare, J. E., Edson, J. E., and McGillis, W.: Parameterization and micrometeorological measurement of air-sea gas transfer, Bound.-Lay. Meteorol., 96, 63-105, 2000.

Fairall, C. W., Yang, M., Bariteau, L., Edson, J. B., Helmig, D., McGillis, W. R., Pezoa, S., Hare, J. E., Huebert, B., and Blomquist, B.: Implementation of the coupled-ocean-atmosphere respones experiment algorithm with $\mathrm{CO}_{2}$, dimethyl sulfide, and $\mathrm{O}_{3}$, J. Geophys. Res., 116, C00F09, doi:10.1029/2010JC006884, 2011.

Johnson, J. E. and Bates, T. S.: Sources and sinks of carbon monoxide in the mixed layer of the tropical South Pacific Ocean, Global Biogeochem. Cy., 10, 347-359, 1996.

Johnson, M. T.: A numerical scheme to calculate temperature and salinity dependent air-water transfer velocities for any gas, Ocean Sci., 6, 913-932, doi:10.5194/os-6-913-2010, 2010.

Jones, R. D.: Carbon monoxide and methane distribution and consumption in the photic zone of the Sargasso Sea, Deep-Sea Res., 38, 625-635, 1991.

Jones, R. D. and Amador, J. A.: Methane and carbon monoxide production, oxidation, and turnover times in the Caribbean Sea as influenced by the Orinoco River, J. Geophys. Res., 98, 2353-2359, 1993. 
Lamontagne, R. A., Swinnerton, J. W., and Linnenbom, V. J.: Nonequilibrium of carbon monoxide and methane at the air-sea interface, J. Geophys. Res., 76, 5117-5121, 1971.

McGillis, W. R., Edson, J. B., Hare, J. E., and Fairall, C. W.: Direct covariance air-sea $\mathrm{CO}_{2}$ fluxes, J. Geophys. Res., 106, 1672916745, 2001.

Najjar, R. G. and Erickson III, D. J.: Modeling the air-sea fluxes of gases formed from the decomposition of dissolved organic matter: carbonyl sulfide and carbon monoxide, in: The Role of Nonliving Organic Matter in the Earth's Carbon Cycle, Berlin, 12-17 September 1993, edited by: Zepp, R. G. and Sonntag, C., John Wiley and Sons, New York, 107-132, 1995.

Nightingale, P. D., Malin, G., Law, C. S., Watson, A. J., Liss, P. S., Liddicoat, M. I., Boutin, J., and Upstill-Goddard, R. C.: In situ evaluation of air-sea gas exchange parameterizations using novel conservative and volatile tracers, Global Biogeochem. Cy., 14, 373-387, 2000.

O'Keefe, A., Scherer, J. J., and Paul, J. B.: CW integrated cavity output spectroscopy, Chem. Phys. Lett., 307, 343-349, 1999.

Rowe, M. D., Fairall, C. W., and Perlinger, J. A.: Chemical sensor resolution requirements for near-surface measurements of turbulent fluxes, Atmos. Chem. Phys., 11, 5263-5275, doi:10.5194/acp-11-5263-2011, 2011.

Stubbins, A., Uher, G., Vassilis, K., Law, C. S., UpstillGoddard, R. C., and Woodward, E. M. S.: The opean-ocean source of atmospheric carbon monoxide, Deep-Sea Res. Pt. II, 53, 1685-1694, 2006.

Stull, R. B.: An Introduction to Boundary Layer Meteorology, Chap. 4, Kluwer Academic Publishers, 1988.

Valentine, R. L. and Zepp, R. G.: Formation of carbon monoxide from the photodegradation of terrestrial dissolved organic carbon in natural waters, Environ. Sci. Technol., 27, 409-412, 1993.
Wanninkhof, R.: Relationship between wind speed and gas exchange over the ocean, J. Geophys. Res., 97, 7373-7382, 1992.

Wilson, D. F., Swinnerton, J. W., and Lamontagne, R. A.: Production of carbon monoxide and gaseous hydrocarbons in seawater: relation to dissolved organic carbon, Science, 168, 1577-1579, 1970.

Woolf, D. K.: Bubbles and their role in gas exchange, in: The Sea Surface and Global Change, edited by: Duce, R. and Liss, P., Cambridge University Press, New York, 173-205, 1997.

Xie, H., Andrews, S. S., Martin, W. R., Miller, J., Ziolkowski, L., Taylor, C. D., and Zafiriou, O. C.: Validated methods for sampling and headspace analysis of carbon monoxide in seawater, Mar. Chem., 77, 93-108, 2002.

Yang, M., Blomquist, B. W., Fairall, C. W., Archer, S. D., and Huebert, B. J.: Air-sea exchange of dimethylsulfide in the Southern Ocean: measurements from SO GasEx compared to temperate and tropical regions, J. Geophys. Res., 116, C00F05, doi:10.1029/2010JC006526, 2011.

Zafiriou, O. C., Andrews, S. S., and Wang, W.: Concordant estimates of oceanic carbon monoxide source and sink processes in the Pacific yield a balanced global "blue water" CO budget, Global Biogeochem. Cy., 17, 1015, doi:10.1029/2001GB001638, 2003.

Zafiriou, O. C., Xie, H., Nelson, N. B., Najjar, R. G., and Wang, W.: Diel carbon monoxide cycling in the upper Sargasso Sea near Bermuda at the onset of spring and in mid summer, Limnol. Oceanogr., 53, 835-850, 2008.

Zuo, Y. and Jones, R. D.: Formation of carbon monoxide by photolysis of dissolved marine organic material and its significance in the carbon cycling of the oceans, Naturwissenschaften, 82, 472474, 1995. 